\title{
EL GÉNERO PICARESCO Y LA NOVELA*
}

Hay pocos testimonios para conocer la recepción de Lazarillo de Tormes durante su siglo y el siguiente. Las noticias y comentarios recopilados por Maxime Chevalier sugieren una lectura limitada a aspectos secundarios: «Los lectores del $\mathrm{XVI}$, incluso los más cultos, no llegan a apreciar la radical novedad del libro» ${ }^{1}$. Lo mismo parece suceder en el siglo XVII. En una obra tan impregnada de literatura como La Dorotea, la evocación del Lazarillo se reduce a una anécdota («iMadre, coco!»). Ya la había recordado Lope de Vega en la Epístola a Barrionuevo, acompañada entonces de una significativa alusión al carácter humilde del relato:

\author{
Acuérdome que escribe Lazarillo \\ (que en tal carta están bien tales autores) \\ que su madre (advertid) parió un negrillo.
}

Otros escritores del XVII (Cervantes, Gregorio González, Quevedo, el autor de Estebanillo González) citaron en diversos momentos el Lazarillo ${ }^{2}$, pero tampoco transmitieron una opinión precisa. Para saber cómo valoraron su estructura los lectores de la época no parece haber mejor documento que las narraciones picarescas, surgidas de una lectura, directa o indirecta, del Lazarillo de Tormes.

\section{Las interpolaciones de Alcalá}

Una especie de continuación constituyen los añadidos de la edición de Alcalá, que se consideran ajenas al autor del relato. La interpolación del tratado primero atañe, principalmente, a la profecía de los cuernos, cuestión en la que no es necesario detenerse aquí. Para los presentes propósitos merecen más interés

* Cf., en este mismo número, Jesús Cañas Murillo, «II Encuentros Juan Manuel Rozas sobre Literatura Española...».

1 Lectura y lectores en la España del siglo XVI y XVII, Madrid, 1976, p. 177.

2 Quevedo parece aludir conjuntamente a La Celestina y Lazarillo cuando elogia "aquella propiedad, grazia i dulzura», en España defendida (ed. Selden Rose, Madrid, 1916, p. 69). Poco antes, Fray José de Sigüenza habia celebrado en el Lazarillo «la propiedad de la lengua castellana, y el decoro de las personas que introduze». Cfr. Historia de la Orden de San Gerónimo, NBAE, XII, p. 145. Otros testimonios sobre el Lazarillo serán mencionados más adelante. 
las líneas finales del fragmento interpolado, en las que se mencionan algunas falsas beatas. Puede parecer reduntante la mención del interpolador a los rezos «por mesoneras, y por bodegoneras y turroneras y rameras, y ansí por semejantes mujercillas» ${ }^{3}$, por quienes reza ahora el ciego. Pero también se puede estimar como un enriquecimiento de la galería de devotas, con lo que ganan en matices la burla antifeminista y la crítica de las falsas oraciones. Parece haber una gradación desde las devotas simplemente necias («mujeres que no parían, malcasadas, preñadas y enfermas») hasta las abiertamente hipócritas, novedad del interpolado. Por lo demás, estas sucesivas particularizaciones de un tipo, constituyen un procedimiento característico de la literatura didáctica, satírica y sermonaria. $L a$ Danza de la muerte, y los Sueños de Quevedo, por citar ejemplos dispares, son dos manifestaciones del mismo fenómeno. Desde las exigencias de un relato centrado en la evolución y experiencias de Lázaro la interpolación no añade nada. Pero si quien escribía pretendía contemplar más tipos y situaciones, entonces su actuación parece guiada por un designio coherente.

Idéntico propósito parece guiar la interpolación del tratado quinto. El nuevo episodio no enriquece la semblanza de Lázaro, ni la del buldero, pero describe la vileza del pueblo. Existe ahí una especie de protagonismo colectivo, momento único en la obra. Supone una culminación de las anteriores descripciones individuales, y un climáx en la crítica de la superstición, particularmente explícita en aquellas palabras del buldero: «¿Qué os paresce, cómo a estos villanos, que con sólo decir cristianos viejos somos, sin hacer obras de caridad se piensan salvar, sin poner nada de su hacienda?». Por último, el breve añadido al final de ese mismo tratado, donde Lázaro admite que le daban de comer ua costa de los curas y otros clérigos do iba a predicar», redondea la burla del estamento eclesiástico.

En cuanto a la última de las interpolaciones - la promesa de seguir escribiendo de «lo que de aquí adelante me suscediere»- su valoración depende de que se vea en el Lazarillo de Tormes un relato cerrado, destinado a explicar un episodio específico - el amancebamiento- o un relato abierto, orientado a dar cuenta de una vida, la cual, al no estar acabada, posibilita su continuidad ${ }^{4}$. La preferencia por esta segunda lectura demuestra que el interpolador vio en la narración de la vida de Lázaro un marco flexible, susceptible de prolongación. También el autor de la Segunda Parte de 1555 empieza su relato repitiendo las últimas palabras de Lázaro en la obra anterior: «En este tiempo estaba en mi prosperidad y en la cumbre de toda buena fortuna, y como yo siempre anduviese...». Su interpretación, literal y estructural, de Lazarillo de Tormes, es idéntica a la del interpolador de Alcalá.

3 La vida de Lazarillo de Tormes y de sus fortunas y adversidades, ed. de Alberto Blecua, Madrid, 1972, p. 106. Todas las citas se harán por esta edición.

4 Interpretaciones divergentes acerca del «caso» pueden verse en Francisco Rico «Problemas del Lazarillo, BRAE (1966), pp. 278-9; Richard Hitchcock, «Lazarillo and Vuestra Merced» MLN, LXXXVI (1971),p. 264-66; Gonzalo Sobejano, «El coloquio de los perros en la picaresca y otros apuntes», $H R$ 43 (1975), pp. 26-32; Victor García de la Concha, Nueva lectura del «Lazarillo», Madrid, 1981, pp. 46 y 82. 
Es evidente que éste pretendió enriquecer los rasgos burlescos y sátiricos. Su quehacer revela, para algún lector moderno, simple incomprensión del Lazarillo. Pero pone de manifiesto que la galería de personajes secundarios le interesó más que la fisonomia del protagonista.

\section{La Segunda Parte de 1555}

La Segunda Parte de Lazarillo de Tormes, y de sus fortunas y adversidades (1555) es una verdadera continuación. Además del título y las palabras iniciales, diversas alusiones ponen de relieve su vinculación con el relato de $1554^{5}$. Lázaro recuerda en varios momentos lances de su vida pasada: la profecía del ciego en Escalona (92b), su labor como pregonero de vinos (93a, 100a, 103b, 107a), y delincuente (100b), el amancebamiento de su mujer (91a, 98a, 106-07). También refiere el desarrollo ulterior de sucesos originados en el primer relato, como el nacimiento de una hija de dudosa paternidad. Al mismo tiempo, amplía circunstancias desconocidas por los lectores; por ejemplo, que su mujer se llama Elvira y el Arcipreste, Rodrigo de Yepes. Otros detalles contribuyen a ese proceso de desvelamiento gradual ${ }^{6}$. Si en Lazarillo de Tormes el protagonista pregonaba «en esta ciudad», «en toda la ciudad», el personaje de la Segunda Parte indica en cierto momento que «dio una gran voz, como la que solía dar en Zocodover» (100b). También algún personaje - como el Arcipreste- ofrece un perfil más acabado, a consecuencia de los nuevos matices aportados.

Del mismo modo que en los capítulos cuatro a seis de Lazarillo de Tormes y en las interpolaciones de Alcalá, la función de Lázaro es la de mostrar otros personajes y ambientes. Lo que define al nuevo protagonista no es tanto la falta de evolución sicológica como las contradictorias facetas que presenta. Una de ellas es la de narrador culto, animado por propósitos docentes. Esto se pone de manifiesto en las digresiones, más extensas y sistemáticas que las breves reflexiones del protagonista de Lazarillo de Tormes. Propiciadas por las aventuras en el fondo del mar, versan en su mayoría sobre cuestiones de gobierno y administración ${ }^{7}$ : la cobardía de los jefes militares (95b), la iniquidad de los señores y su mal ejemplo sobre los criados (101a), los testigos falsos (103b), los jueces (104a), los privados (105a). En ciertos momentos Lázaro echa mano del ejemplo histórico para reforzar sus argumentos, como se ve en las alusiones a Cayo Fabricio (96a), Alejandro (96b), Gonzalo Hernández (96b), Escipión (101b), Aníbal (100a), Alejandro y Calístenes (105a), el rey de Persia (104a). En algún caso el lugar inartificial procede de la Biblia (104a) o de un autor clásico (103a). Manos frecuente es que Lázaro diserte sobre cuestiones no políticas, como hace a propósito de los «hombres parlones» (104b).

5 Las relaciones de carácter material y bibliográfico entre La vida de Lazarillo y la Segunda parte han sido analizadas por A. Rumeau, «Notes au Lazarillo. Les éditions d'Anvers, 1554-1555 de $L a$ vida de Lazarillo et de la Segunda parte», BHi 66 (1964), pp. 257-71.

6 Una valoración diferente la ofrece José Caso González, «Introducción de su edición de Lazarillo de Tormes, Barcelona, 1984², pp. LXVII-LXVIII.

7 Sigo la edición de José Aribau, $B A E$, III, Modernizo la acentuación. 
Otras veces la enseñanza transmitida es de carácter negativo, mera ridiculización de un vicio o persona. En tales supuestos el otrora sermoneador Lázaro se limita a adoptar un tono burlesco, como ocurre con «alguno de aquellos abades o mantilargos, que se llaman hombres de licencia» (108a), entre los que el protagonista sienta plaza de sabio. El mismo tono se observa en el relato de los clérigos que abandonan a los naúfragos: «como decíanse ser caballeros de Jesucristo, fuéronse en compañia de los otros y dejáronnos por ruines».

No siempre narra Lázaro desde la gravedad del moralizador o la superioridad del satírico. En ocasiones se incluye en los personajes merecedores de su burla, como ocurre durante su estancia en la Universidad de Salamanca. La ignorancia del rector y de los licenciados queda puesta de relieve por el hecho de estar al mismo nivel del protagonista, que no duda en reconocer su incultura, glotonería y afición al juego, de manera que la propia denigración alcanza, fundamentalmente, a los demás.

Todo ello no impide reconocer la existencia de fragmentos donde la comicidad carece de cualquier fin satírico. El capítulo primero, donde Lázaro expone su situación antes de partir para Angel, abunda en momentos y expresiones que sólo pretenden la risa por sí misma. Igualmente, dentro del fragmento más grave de la obra, la narración de la estancia entre los atunes, hay comentarios jocosos carentes de cualquier finalidad didáctica.

Esa variedad de funciones y actitudes va en detrimento de la coherencia sicológica del protagonista. Pero exigir al Lázaro de 1555 las características de un personaje novelesco implica valorarlo por relación a lo que no es. Constituye básicamente un yo narrativo, más que un personaje con entidad caracterológica. Es un elemento funcional, hilo conductor de un relato didáctico, satírico $\mathrm{y}$, también jocoso. Su incoherencia «humana» se convierte en un requisito técnicamente necesario para abarcar las diferentes situaciones que desea contemplar su autor. Este yo narrador no difiere, sustancialmente, del yo moralizador del Eclesiastés, contradictorio e incoherente en más de un aspecto. $\mathrm{O}$ del yo del Libro de buen amor, donde un didactismo de carácter muy heterogéneo condiciona la fisonomía de un personaje cambiante y multiforme.

Con independencia de la valoración que se haga del relato de 1555 , parece claro que el personaje narrador de 1554 -de modo especial, el de los tres primeros capítulos - resultaba inadecuado para referir las nuevas aventuras de la $\mathrm{Se}$ gunda Parte. Y no sólo para referirlas, sino también para comentarlas. Hay aquí otra faceta que conviene tener en cuenta. Se percibe sin dificultad la actitud del autor cuando el segundo Lázaro ofrece reflexiones políticas, se burla de los clérigos o satiriza a los universitarios salmantinos, porque ante cada específica exigencia didáctica o satírica el personaje es manipulado de manera transparente. De este modo se disipa la ambigüedad, tantas veces señalada ${ }^{8}$, de Lazarillo de

8 Su origen es explicado así por R. W. Truman: «Moreover, although this irony presents itself as the expresion of one who has undergone very considerable moral corruption, it can probably be said that the manner of narration and presentation invites one to share in Lázaro mood and attitude, that is, in his sense of the fun of being irreverent and disrespectful, rather than to stand apart from him and note the fact that this sense of fun has much to do with an amoral, unprincipled outlook 
Tormes, tras cuya lectura «the reader is intentionally left baffled about one or more questions raised by the work ${ }^{9}$.

La cuestión del narrador lleva aparejada la de su destinatario. Lázaro sigue relatando a "Vuestra Merced» el conjunto de su vida, de la que forma parte, como un episodio más, el amancebamiento de su mujer. Incluso sugiere una comunicación epistolar abierta al futuro:

Contóme cosas maravillosas que había pasado con todos géneros de gentes, lo cual si a vuestra merced hubiese de escribir sería largo, y fuera de lo que toca a mis trabajos. Cuando sea vuestra merced servido, si quisiere, le enviaré, la relación de lo que con ella pasé. (p. 105b).

Esto es lo sucedido después de la ida de Arjel; lo demás con el tiempo lo sabrá vuestra merced, quedando muy a su servicio. (p. 109b).

Ese sostenido interés en conocer la vida del pregonero no aparece justificado en ningún momento. el anónimo autor de 1555, igual que el interpolador de Alcalá, interpreta el Lazarillo de Tormes como un relato prolongable. Por eso convirtió al destinatario en un pretexto, mero receptor de todo cuanto quisiera contar el protagonista. El cambio operado en el papel de «Vuestra Merced» propicia la prolongación del relato y la yuxtaposición de episodios, en consonancia con la estructura y el contenido de la Segunda parte.

Hay que tener en cuenta, además, que junto a «Vuestra Merced», destinatario principal, Lázaro invoca a otras personae fictae. Apostrofa a Alejandro y a Gonzalo Hernández (p. 96b) lamentando la mezquindad del general de los atunes. Poco más adelante escribe: «consuélense los que en la tierra se quejan de señores», tras haber mostrado su experiencia con los del mar. En otro lugar, Lázaro invita a los litigantes «y hombres que os quejáis que vuestro contrario hace mala probanza con número de testigos falsos» a que se conformen con su situación: «venid, venid al mar, y veréis la poca razón que tenéis de os quejar en la tierra» (p. 103b).

Cada narrador dispone de su narratario ${ }^{10}$, por lo que las variaciones del primero propician las del segundo. La pluralidad de facetas de Lázaro implica una simétrica pluralidad de destinatarios. En cuanto biógrafo de su existencia, se diri-

on life. In the measure that one reacts to Lázaro and his story in this way, a predominantly serious, moral response to the Lazarillo becomes the more difficult». Cfr. «Parody and Irony in the Self-Portrayal of Lázaro de Tormes» MLR, 63 (1968), p. 605. Este mismo crítico señala en otro lugar («Lázaro de Tormes and the Home novus Tradition», MLR, 64 (1969), p. 67), que la actitud irónica que Lázaro «adopts towards himself and his achievements» no afecta a «the details of the presentation of Lázaro's masters». Probablemente este hecho explica el contraste entre la transparencia de la sátira clerical, cuya intención resulta inequivoca, y la dificultad que puede experimentar el lector al enjuiciar el comportamiento de Lázaro. La actitud del autor es fácil de adivinar en el primer caso, pero no sucede lo mismo en el segundo.

9 Wayne Booth, The Rhetoric of Fiction, Chicago, $1970^{9}$, p. 297. Lazarillo de Tormes constituiría un caso de confusión debido al authorial silence.

10 Entendiendo, con Gérald Prince, que es «quelqu' un à qui le narrateur s'adresse» y dando por sentido que, al igual que el narrador, «est une crẻature fictive»; Cfr. "Introduction à l'étude du narrataire», Poétique, 14 (1973), p. 178. 
ge a Vuestra Merced; en cuanto adoctrinador de asuntos públicos, invoca irónicamente a quienes sufren injusticias. La apelación a éstos es una figura elocutiva destinada a mover los afectos. ya Luis de Granada señalaba que «es mucho más acre la exclamación, cuando se junta con el apóstrofe»" ${ }^{11}$, y al autor de la Segunda parte no dudó en incorporar a la narración un recurso retórico extensamente cultivado por toda suerte de obras didácticas.

La Segunda parte es un relato misceláneo. Las páginas que presentan a Lázaro en Toledo siguen el Lazarillo de Tormes; la aventura entre los atunes (transformación y viaje a un mundo fantástico), el modelo lucianesco; el apólogo de la verdad entronca con una fuente todavía no conocida ${ }^{12}$, en tanto que el debate en la Universidad de Salamanca parece poseer un modelo preciso ${ }^{13}$. El autor de la Segunda parte vio en el Lazarillo un esquema constructivo flexible que permitía, además de una prolongación, su acomodación a tradiciones literarias diversas, para desarrollar una sátira de contenido vario.

El autor de 1555 interpretó el Lazarillo de Tormes a la luz de los gustos literarios del momento. El Asno de oro sugería el relato de episodios yuxtapuestos, la transformación del protagonista en animal, la consiguiente perspectiva inédita con fines satíricos. A su vez, otras obras de la sátira menipea inducían a enriquecer el Lazarillo de Tormes con notas fabulosas, mezclando elementos serios y cómicos, estableciendo contrastes de tono y estilo. Como indicó Gonzalo Sobejano, «si esta continuación comete el grave pecado de transformar la historia creíble del muchacho hambriento en una época e inverosímil alegoría, pasando así de un género a otro muy diverso, algún elemento del primer Lazarillo daría pie al continuador para proseguir la obra como lo hizo"s ${ }^{14}$.

El siguiente comentario de Alberto del Monte ${ }^{15}$ :

La anónima Continuación del Lazarillo del Tormes, publicada en 1555, ya no tiene nada en común con el género picaresco. Es una fábula de metamorfosis alegórica, estimulada por el mismo gusto que ya había motivado el Diálogo de las transformaciones, el Crotalón y la ya citada versión castellana del Asno de Oro de Apuleyo, y se remonta a la tradición de la sátira lucianesca más que a la novela picaresca.

es certero en lo esencial, pero se sitúa en una perspectiva posterior en el tiempo, pues hacia 1555 no había más «género picaresco» que esas dos obras. Lo «picaresco», pues, consistía en la presencia de Lázaro de Tormes, una ambientación en los estratos bajos de la sociedad y una proliferación de personajes satirizables.

11 Retórica eclesiástica, trad. española, BAE, 11, p. 551b.

12 Cfr. Robert H. Williams, «Notes on the Anonymous Continuation of Lazarillo de Tormes», Romanic Review, XVI (1925), pp. 223-35; Marcel Bataillon, Novedad y fecundidad del «Lazarillo de Tormes», trad. española, Madrid, 1968, pp. 85-87. Caso González, lec. cit., pp. XLVIII-LV; Asunción Rallo, edición de El Crótalon, Madrid, 1982, pp. 405-06.

13 Según Bataillon, el episodio se inspira «en la $28^{\text {a }}$ historieta de Ulenspiegel, en la que el héroe responde a las preguntas propuestas por la Universidad de Praga». Cfr. Novedad y fecundidad del "Lazarillo de Tormes», p. 88.

14 Forma literaria y sensibilidad social, Madrid, 1967, p. 24.

15 Itinerario de la novela picaresca española, trad. española, Barcelona, 1971, p. 61 . 


\section{Guzmán de Alfarache}

Con Guzmán de Alfarache parece haberse alcanzado lo que denominó Américo Castro "el auge de la novela picaresca» ${ }^{16}$. Lazarillo de Tormes pudo haber sugerido a Alemán varios elementos: relatos retrospectivo, explicación de un estado final, protagonista mozo de muchos amos ${ }^{17}$. Pero las semejanzas entre ambas narraciones no ocultan las apreciables diferencias. Para empezar, el Guzmán se diferencia en todo lo relacionado con la perspectiva narrativa: motivos de la autobiografía, relación del narrador y el autor, relación del narrador y su destinatario. En otras cuestiones, tales como el estilo o la promesa de una continuación, el Guzmán también se aparta del Lazarillo, o cuando menos, apura hasta las últimas consecuencias las posibilidades insinuadas en el primer relato.

La perspectiva narrativa de las dos obras es aparentemente idéntica, pero funcionalmente distinta ${ }^{18}$. En primer lugar varía la motivación de la autobiografía ${ }^{19}$. El pregonero escribe a petición de un personaje, mientras que Guzmán lo hace a causa del «deseo que tenía, curioso lector, de contarte mi vida» ${ }^{20}$. Esta justificación (que recuerda, por ejemplo, el inicio del Asno de oro) no se distingue de la que expone Mateo Alemán al dirigirse al discreto lector: «Y tú, deseoso de aprovechar, a quien verdaderamente consideré cuando esta obra escribía». Es decir, la autobiografía del galeote depende de su voluntad docente. La coincidencia entre las palabras del autor y las del narrador, así como la indiferenciación entre el lector real (invocado por Guzmán) suponen en la práctica una fusión (rayada en la confusión) entre autor y narrador. Exactamente lo contrario de lo que ocurre en Lazarrillo de Tormes.

De Guzmán se podría decir lo que del narrador agustiniano: «it is faith alone that gives the narrator this timeless vision of his temporal life, enabling him to survey his past wanderings from a stationery exterior point» ${ }^{21}$. Fe en lo religioso, cultura y recta disposición moral («un hombre de claro entendimiento, ayudado de letras y castigado del tiempo») constituyen la fisonomía de un narrador sustancialmente distinto del de Lazarillo de Tormes. Lo destacable no es sólo la bondad moral desde la que se narra, sino también la condición inequívoca del mensaje, aspecto que el propio Alemán garantiza desde el Prólogo al «discreto lector» y la Declaración para el entendimiento de este libro.

16 El pensamiento de Cervantes, Madrid, 1925, p. 234.

17 Cfr. Gonzalo Sobejano, Forma literaria y sensibilidad social, pp. 11-30; Lázaro Carreter, «Lazarillo de Tormes» en la picaresca, Barcelona, 1972, pp. 206-207.

18 «Both autobiographical in presentation, the first-person mode of telling is different functionally, structurally, and convers totally different ideological content in the two works», cfr. Peter Dunn. «Problems of a Model for the Picaresque and the Case of Quevedo's Buscon, BHS, LIX (1982), p. 98. Anteriormente, Alfonso Rey, «La novela picaresca y el narrador fidedigno», $H R 47$ (1979), pp. 61-63, junto con la bibliografía ahí citada.

19 Tal vez porque es distinta la fuente. Al respecto, Francisco Rico, «Introducción» a La novela picaresca española, I, Barcelona, 1970, pp. CXIII-CXIV, así como Michel Cavillac, Gueux et marchands dans le «Guzmán de Alfarache» (1599-1604), Université de Bordeauz, 1983, pp. 347-49.

20 Edición de Francisco Rico, La novela picaresca española, p. 105.

21 William Spengeman, The Forms of Autobiography, Yale university Press, 1980, p. 7. 
Las novedades del Guzmán de Alfarache guardan relación con el otro polo de la perspectiva: el narratario. Los hechos que refieren Lázaro y Guzmán están condicionados por sus respectivos lectores. El de Lázaro - Vuestra Merced-posee una curiosidad restringida a un episodio específico, por lo que sería inadecuado para recibir las lecciones de Guzmán. Nada más natural, por ello, que la solución ensayada por Alemán fuese muy distinta a la contenida en Lazarillo de Tormes, y algo parecido a la de la Segunda parte.

La relación epistolar de Lázaro-Vuestra Merced constituía un marco estrecho para quien quisiera introducir elementos didácticos. El primer autor la aprovechó hasta el tope de sus posibilidades ${ }^{22}$. El interpolador de Alcalá la vulneró. El autor de la Segunda parte, además de vulnerarla, introdujo nuevos destinatarios. Mateo. Alemán renunció a ella.

Guzmán escribe para un «curioso lector». Lo indica en las palabras inicales y lo reitera el comienzo de la segunda parte (II, 1, 1). Tras descartar la posibilidad de acomodarse a todos los gustos

Querrían el melancólico, el sanguino, el colérico, el flemático, el compuesto, el desgarrado, el retórico, el filósofo, el religioso, el perdido, el cortesano, el rústico, el bárbaro, el discreto y aún la señora Doña Calabaza que para sola ella escribiese a lo fruncido y que con sólo su pensamiento y a su estilo me acomodase. No es posible;

especifica para quién escribe:

$\mathrm{Y}$ tú, discreto huésped que me aguardas, pues tienes tan clara noticia de las miserias que padece quien como yo va perigrinando, no te desdeñes cuando en tu patria me vieres y a tu puerta llegare desfavorecido, en hacerme aquel tratamiento que a tu propio valor debes. Pues a ti sólo busco y por ti este viaje (p. 490).

Así pues, Guzmán se dirige a un destinatario acomodado a sus deseos. Sumiso, instruido, con celo de aprender, le otorga la máxima libertad en la orientación de su relato, de sus admoniciones y de sus apóstrofes. A este lector, además, lo puede pintar en situaciones concretas (por ejemplo, tratando con los vanos [I, II, 3] pp. 263-64), a fin de que la enseñanza quede evidenciada de forma concreta. Esto da al destinatario de Guzmán una fisonomía cambiante, ajustada a las conveniencias didácticas de cada momento.

No cesan ahí, sin embargo, las facilidades de que goza el narrador para invocar al narratario más adecuado en cada momento. Porque Guzmán apostrofa en muchas ocasiones a personajes distintos del lector discreto para quien escribe. Así, el rico (p. 262), el que persigue vanas honras (p. 264), el mocito de guitarra con pretensiones elevadas (p. 265), el señor que no retribuye debidamente a sus cria-

22 Aunque el pregonero escribe para un solo destinatario, «there are times when Lazarillo seems quite oblivious to the omnipresence of Vuestra Merced and utterly engrossed in the pleasure or poignancy of his own reminiscences» (Helen Reed, The Reader in the Picaresque Novel, London, 1984, p. 45). Además, como señaló Víctor G. de la Concha (op. cit., p. 73), "'Vuestra Merced' queda englobado en la intencional masa de destinatarios». Justamente en los apartes y en la invocación a otros lectores se encuentran las consideraciones críticas más significativas del Lazarillo, lo que implica que tampoco esta obra contiene, rigurosamente hablando, un único narratario. 
dos (p. 296), otra vez el rico, etc. Como es sabido, el relato de Mateo Alemán sigue en buena parte la inventio, la dispositio y la elocutio de la literatura sermonaria. También se ha podido decir del Guzmán que «se presenta a nuestros ojos como un mosaico de sermones y de relatos breves perfectamente estructurados en sí mismos» ${ }^{23}$. Es evidente que los sucesivos «sermones» de Guzmán exigen en ciertos casos destinatarios diferentes del discreto «lector». De esta manera coincide Guzmán de Alfarache con la Segunda parte de 1555 en el hecho de que fragmentos del relato van dirigidos a un narratario distinto del principal. Esta coincidencia entre dos obras tan diferentes no necesita explicarse por influencia directa, de la primera sobre la segunda, sino como muestra de que el propósito doctrinal obliga a la utilización de unos mismos recursos técnicos.

La segunda cuestión que merece ser aludida atañe al estilo. Desde que Gracián ensalzó la naturalidad de la prosa de Alemán ${ }^{24}$, se ha venido insistiendo en su. llaneza. La relativa abundancia de expresiones coloquiales y la circunstancial aproximación de la lengua escrita a la hablada, pueden justificar la impresión de que el Guzmán comparte el ideal estilístico del Lazarillo ${ }^{25}$. Pero no sucede lo mismo si la comparación se efectúa desde el punto de vista de la compositio, es decir, la ordenación sintáctica, máxime si se toman como punto de referencia los pasajes no narrativos del Guzmán. En sus disertaciones, en efecto, el galeote echa mano de recursos característicos de la prosa didáctica, en sus diferentes modalidades; desde la yuxtaposición del estilo senequista a la compleja subordinación del período circular. Sin olvidar elementos propios de la prosa simétrica: parison, isocolon, antimetabole, anáfora y similicadencias ${ }^{26}$. De forma nítida e imperfecta, aislada o combinada confluyen en el Guzmán de Alfarache, procedimientos empleados por oradores, tratadistas y predicadores: Séneca, Cicerón, Antonio de Guevara, Fray Luis de Granada, Quevedo, etc. Gracián no analiza esa importante faceta del estilo de Alemán, pero proporciona los medios para hacerlo. En el discurso LXI de la Agudeza señala la presencia de dos estilos básicos, el asiático y el lacónico, advirtiendo que «El dilatado es propio de oradores; el ajustado, de filósofos morales». Tras lo cual, prosigue: «Los historiadores se bandean lisonjeando el gusto con su agradable variedad. Más que vulgar ignorancia es querer ajustar un historiador a la seca narración de los sucesos, sin que comente, pondere, ni censure» ${ }^{27}$. La poética historia de Guzmán cultiva una variedad estilís-

23 Celina S. de Cortázar, «Notas para el estudio de la estructura del Guzmán de Alfarache», Fil, VIII (1962), p. 85.

24 En Agudeza y arte de ingenio, elogia la Atalaya como ejemplo de «estilo natural», entendiendo por tal el «liso, corriente, sin afectación, pero propio, casto y terso». Cito por la edición de Correa Calderón, Madrid, II, 1969, pp. 244 y 242, respectivamente. Cuando comenta el estilo del Guzmán, Gracián selecciona pasajes narrativos, en este caso un fragmento de la historia de Ozmín y Daraja.

25 En La novela picaresca española, pp. CLXIII-CLXXI, Francisco Rico recoge los comentarios más significativos, antes de exponer su propio análisis del estilo del Guzmán. En las páginas LXXILXXV, comenta el estilo del Lazarillo.

26 Para la simetria prosística puede verse G. K. Hunter, John Lyly, the Humanist as Courtier, London, 1962, pp. 264-70 y Brian Vickers, Francis Bacon and Renaissance Prose, Cambridge, 1968, pp. 96-140.

27 Agudeza y Arte de ingenio, II, p. 236. 
tica donde la prosa «de los oradores» y la de los «filósofos morales» ocupan un lugar destacado.

En cuanto a la proyectada Tercera parte de la vida del Guzmán de Alfarache, se trata de un dato que no puede ser soslayado. Las menciones a tal continuación son varias e inequivocas ${ }^{28}$. Aunque se debieran a razonez de rivalidad editorial, su simple promesa indica que el autor considera prolongable su relato. También Cervantes quise cerrar la puerta a los plagiadores, y para ello adoptó la solución más sencilla, haciendo morir a Don Quijote. Guzmán se despide de su lector en términos que no dejan lugar a dudas:

Aquí di punto y fin a estas desgracias. Rematé la cuenta de mi mala vida. La que después gasté, todo el restante della verás en la tercera y última parte. (p. 905).

Guzmán redacta sus memorias años después de los últimos sucesos narrados, a la vez que promete contar más cosas notables, actitud que recuerda la interpolación de Alcalá y la Segunda parte de 1555, donde el Lazarillo era entendido como un relato susceptible de seguir ampliando la galería de tipos y situaciones. Para Celina S. de Cortázar, el Lazarillo se ofreció como modelo a Alemán en lo que tenía de «narración abierta y floja» ${ }^{29}$. La misma laxitud que permitió insertar ejemplos, fábulas, apólogos, sentencias, sermones y relatos de procedencia varia ${ }^{30}$ hacía posible el anuncio, aunque fuese insincero, de una continuación.

Alemán, para escribir un relato didáctico, siguió libremente el Lazarillo, del que se aleja radicalmente en algunos casos. Su particular lectura se traduce en las novedades técnicas indicadas.

\section{Las continuaciones del Lazarillo y del Guzmán}

Para completar el recorrido por las primeras creaciones picarescas conviene alterar el orden cronológico, tomando en consideración las continuaciones del $L a$ zarillo y del Guzmán. El carácter tardío de algunas no impide entroncarlas con sus proclamados antecesores, por lo que su análasis puede hacerse inmediatamente después.

La Segunda parte de la vida de Lazarillo de Tormes (1620) de Juan de Luna, encontrada en «unos cartapacios en el archivo de la jacarandina de Toledo», pretende contrarrestar los "disparates tan ridículos como mentirosos» ${ }^{31}$ del Lazarillo de 1555. La ficción del manuscrito que contiene la historia del héroe recuerda

28 Véanse, en la edición citada, las páginas 466, 468, 488 y 489. Angel San Miguel, tras recoger los comentarios suscitados por esa promesa de Mateo Alemán, analiza el problema de un modo detallado y convincente. Cfr. "Tercera parte de Guzmán de Alfarache». la promesa de Alemán y su cumplimiento por el portugués Machado da Silva», Iberoromania, I (1974), pp. 95-104.

29 Art. cit., p. 86.

30 Como puso de relieve Edmond Cros, Protée et le gueux: Recherches sur les origines et la natura du récit picaresque dans «Guzmán de Alfarache», París 1967, pp. 180 y ss., así como Contribución à l'étude des sources du "Guzmán de Alfarache», Montpellier, 1967.

31 Edición de Joseph Laurenti, Madrid, 1979; p. 5 para las dos citas. 
artificios semejantes de los libros de caballerías. Tal influencia, de existir, se limita al marco del relato. El contenido, es decir, la narración en primera persona a cargo de Lázaro, tiene evidentes conexiones con los Lazarillos, como se manifiesta en la reaparición de personajes ya conocidos (el arcipreste, Elvira, el hidalgo), la evocación del ciego, la ubicación en Toledo, los preparativos de la campaña de Argel y otros detalles análogos.

Más interés ofrecen los aspectos que atañen a la contrucción literaria. Con respecto a los Lazarillos anteriores, Luna intensifica el carácter burlesco del relato, perceptible en la caracterización del protagonista y de los personajes secundarios. Paralelamente, se hace más patente la sucesión de estampas satíricas, donde son ridiculizados, preferentemente, mujeres y eclesiásticos. Luna no pretende adoctrinar, sino degradar, por lo que su relato está exento de enseñanzas positivas, no pudiendo considerarse como tales algunas reflexiones morales dispersas. Respecto al narratario, Lázaro dirige su relato al lector, invocado algunas veces de forma explícita («benigno lector», capítulo IV), y, más comúnmente, sobreentendido («Preguntad a un filósofo», cap, IX). Por último, también aquí se anuncia una continuación de las aventuras del héroe, aunque la promesa de una nueva parte corresponde al autor y no al personaje narrador.

Los relatos de 1555 y 1620 divergen en ciertos aspectos, pero coinciden en otros, precisamente los que muestran la estructura y la técnica característica de las obras satíricas: 1) protagonista itinerante, carente de entidad humana; 2) sucesión de episodios tenuemente trabajos; 3 ) construcción abierta a posibles prolongaciones; 4) tratamiento de la realidad degradante, que propicia la ridiculización; 5) uso de la primera persona que permite reconocer las ideas del autor; 6) utilización de un destinatario muy flexiblemente mencionado por el narrador.

La Segunda parte de la vida del pícaro Guzmán de Alfarache, pese a sù inferioridad estética, posee interés porque resalta aspectos visibles del modelo. Martí, ajustándose al primer Guzmán, mantuvo el carácter discursivo del protagonista, la sucesión de digresiones y la intención docente. Esto se percibe, incluso, en aspectos menores del libro, como ocurre con el minúsculo relato picaresco de un personaje secundario, Francisco de León $(I, 1)$, relato sembrado de reflexiones que abarcan desde la autoacusación hasta la disertación sobre cuestiones varias.

Respecto a la Tercera parte de la vida de Guzmán de Alfarache, ya quedó indicado que la promesa de una continuación en la vida de Guzmán era un dato merecedor de atención. No sólo por la posibilidad de que Alemán la hubiera proyectado o escrito, sino por el mero hecho de que considerase su relato susceptible de continuación. Esa prolongación tuvo lugar en la obra de Félix Machado de Silva, escrita hacia 1650, cuyo comienzo se sitúa en el momento en que Guzmán espera en la galera su libertad.

La obra de Machado de Silva arranca de un protagonista ya virtuoso, que irá acrecentando su bondad hasta hacerse ermitaño, después de haber tomado el hábito de San Francisco. El nuevo Guzmán «es, en muchos capítulos, menos el ejecutor real de los sucesos, que su testigo ocular, cuando no su mero auditor» ${ }^{32}$. 
Tan certera observación de Angel San Miguel no debe inducir a la creencia de que Machado de Silva es el primero que relega al protagonista a la mera condición de narrador. Ese proceso empieza en Lazarillo de Tormes y se acentúa en sus continuaciones, así como en otros relatos picarescos, de los que Marcos de Obregón constituye un ejemplo nítido. Las diferencias psicológicas y morales de los diversos personajes no ocultan la identidad de su papel estructural.

Por lo demás, el hecho de que Machado de Silva escribiese un largo relato con un protagonista virtuoso demuestra su voluntad didáctica, poco original en su contenido y en sus rasgos formales, pero indicativa de la idoneidad del género picaresco para albergar actitudes moralizadoras.

\section{Otros relatos}

Cada uno de los restantes picarescos ofrece unas peculiaridades cuyo análisis no procede en este lugar. Pero varios rasgos estructurales o funcionales se reiteran: a) el narrador; b) su destinatario; c) construcción abierta.

a) La indefinición ideológica del Lazarillo de Tormes, evitada por diferentes medios en la Segunda parte y Guzmán de Alfarache, no reaparece. Unas veces porque el autor tiene un preciso portavoz en el narrador, sea éste en primera persona (Marcos de Obregón, El donado hablador, La desordenada codicia) o en tercera (La ingeniosa Elena, El Bachiller Trapaza). Otras veces porque aparece claramente distanciado de un personaje-narrador inmoral o risible (Buscón, Gregorio Guadaña, Lazarillo de Juan de Luna, Estebanillo González) ${ }^{33}$. Las dudas interpretativas que suscitan algunos aspectos de esas obras (y otras como Guitón Honofre o La pícara Justina) no se deben a confusión entre autor y narrador.

La voluntad crítica o educativa de estos relatos implica la subordinación de los personajes a las ideas del autor. El polilingüismo que, según Bakhtin,"caracteriza a la novela, "C'est le discours d'autrui dans le langage d'autrui, servant à réfracter l'expresión des intentions de l'auteur» ${ }^{34}$. Pero en el discurso del pícaro hablador ${ }^{35}$, más que refracción, hay intrusión del autor. Esta circunstancia se percibe en el prólogo y apartes del Lazarillo en diversas digresiones e historias intercaladas del Guzmán, en el lenguaje del Buscón y, desde luego, en las demás obras ${ }^{36}$.

33 He tratado de poner de relieve este aspecto de la picaresca en «La novela picaresca y el narrador fidedigno», citado antes. Sigo manteniendo la tesis defendida en ese artículo, aunque no diversos pormenores del mismo.

34 Esthétique et théorie du roman, trad. francesa, Paris, 1978, p. 144.

35 Por utilizar la designación de Gonzalo Sobejano, «Un perfil de la picaresca: el pícaro hablador», Studia hispanica in honorem Rafael Lapesa, Madrid, 1975, III, pp. 467-85.

36 Respecto al Lazarillo, remito a lo indicado en la nota 22. Para las intrusiones del autor en el lenguaje de Guzmán de Alfarache, véanse: Moreno Báez Lección y sentido del «Guzmán de Alfarache», Madrid, 1948, p. 48; Angel San Miguel, Estructura y sentido del «Guzmán de Alfarache», Madrid, 1971 p. 200; Edmond Cros, Protée et le gueux, p. 194. Con relación al Buscón, Harry Sieber, «Apostrophes in the Buscón: an Approach to Quevedo's Narrative Technique», MLN, 83 (1968), p. 211. 
b) A diferencia del Lázaro de 1554 , los demás pícaros no cuentan su vida para satisfacer la curiosidad de un destinatario específico. El protagonista de Juan de Luna, por ejemplo, no indica para quién escribe. Los del Buscón y Lazarillo de Manzanares invocan a un Vuestra merced que sólo es un nombre. En Guitón Honofre, Pícara Justina (ambos narradores), Gregorio Guadaña, Teresa de Manzanares y Estebanillo González se dirigen a un lector que moldean a su conveniencia. Además, algunos apostrofan adicionalmente a más destinatarios, siguiendo el ejemplo del segundo Lázaro y de Guzmán. Así hacen Honofre, Justina y Pablos. Idénticamente ocurre cuando el narrador en tercera persona invoca a diferentes destinatarios (La ingeniosa Elena) o utiliza un plural inclusivo del lector (Bachiller Trapaza, La garduña de Sevilla).

Incluso cuando el destinatario convive con el narrador no deja de ser un simple punto de apoyo. Esa es la función del vicario y el cura de San Zoles en El donado hablador, similar a la de tantos interlocutores en los diálogos didácticos y satíricos del Renacimiento (Diálogo de la lengua, De los nombres de Cristo, El Crotalón, Filosofía antigua poética, etc.). Parecida función cumplen el ermitaño que escucha a Marcos de Obregón, o el «autor» que siente curiosidad por conocer la vida de Andrés en $L a$ desordenada codicia.

Al no estar el narrador sometido a un preciso requerimiento de información, el relato se orienta más fácilmente hacia el muestrario de tipos y costumbres. Ese propósito parece explicar la coincidencia de tantas obras en su uso del narratario ${ }^{37}$.

c) Varias narraciones dejan explícitamente abierta la posibilidad de una continuación. A las ya vistas hay que añadir La pícara Justina, Guitón Honofre, el Buscón, Guzmán apócrifo, Teresa de Manzanares, Bachiller Trapaza y La garduña de Sevilla. Aunque la promesa de segundas o terceras partes sea un tópico intrascendente o un ardid comercial, su formulación implica que el autor considera teóricamente posible la prolongación del relato, lo cual, a su vez, es una consecuencia de la estructura laxa y abierta del mismo ${ }^{38}$. Esto pone de relieve que la biografía del personaje interesa menos como trayectoria individual que como espejo y comentario de ambientes.

El que obras tan distintas ofrezcan similitud funcional en cuestiones vertebrales de estructura y técnica sólo puede explicarse por la identidad de propósitos que las guía. Hay una estrecha dependencia entre la manipulación del protagonista, la relación narrador-narratario y la estructura flexible de la trama. En varios momentos he esbozado la opinión, que no es original, de que la narrativa picaresca delata una inspiración satírica. Antes de insistir sobre este punto, convendrá abordar otras cuestiones colaterales.

37 En 1984 aparecen dos estudios que se ocupan del narratario en la picaresca, superando el marco de una sola obra: el ya citado libro de Helen Reed (para Lazarillo, Guzmán y Buscón) y el artículo de Darío Villanueva «Narratario y lectores implícitos en la evolución formal de la novela picaresca», Homenaje en honor a [sic] Ricardo Gullon, Lincoln, Nebraska, 1984, pp. 343-67.

38 Con toda sencillez había formulado Samuel Gili Gaya una observación idéntica en Historia general de las literaturas hispánicas, ed. Guillermo Díaz Plaja, Barcelona, 1953, III, pp. 99-100. 


\section{El género picaresco}

Parece difícil reconstruir una hipotética preceptiva de la picaresca. Las manifestaciones de los creadores o las referencias de unas obras a otras son escasas y lacónicas, siendo lo más significativo su carencia de pretensiones teóricas. Pese a la precariedad de tales indicios, su examen puede ayudar a conjeturar la posible conciencia que del género picaresco tuvieron sus cultivadores.

Desde siempre se ha señalado la inferioridad estética del Guzmán apòcrifo. Eso no impide reconocer su interés histórico-literario, como sucede a menudo con obras de segunda fila. Los plagiarios ponen de relieve las expectativas y gustos que se apresuran a satisfacer, y así ocurre con la obra de Juan Martí. Uno de sus rasgos más llamativos es el título: Segunda Parte de la vida del pícaro Guzmán de Alfarache, porque implica la conciencia oficial de un tipo de narración caracterizado por la presencia de un pícaro como protagonista.

Aunque Alemán parece lamentar el hecho de que a su Atalaya de la vida humana «dieron en llamarle Pícaro y no se conoce ya por otro nombre» (p. 546), él mismo proporcionó elementos para tal denominación. Diego Dávila, en su aportación, dice haber visto «un libro intitulado Primera parte del Pícaro Guzmán de Alfarache» (85). En la dedicatoria a Francisco de Rojas, Alemán anuncia su propósito de hacer «de un desechado pícaro un admitido cortesano» (90). En el prólogo al «discreto lector» le invita a «moralizar según se te ofreciere», no siendo obstáculo la existencia de momentos no graves, porque «eso es el ser de un pícaro sujeto desde libro» (94). Alonso de Barros celebra que Mateo Alemán hubiese pintado tan a lo vivo un hijo del ocio «de forma que pudiera servir de ejemplo y dechado a los que se dispusieran a gozar de semejante vida» (97), y Hernando de Soto elogia en el libro «Dos grandes cosas, que son: /Pícaros con discreción / Y autor de grave sujeto» (101). También Guzmán utiliza en repetidas ocasiones esos términos. Bastará recordar su alabanza del «almíbar picaresco» frente a la vanidad de la honra (p. 261), o la manera en que detiene su crítica a los estados, «que más es doctrina de predicación que de pícaro» (p. 271).

Un lector atento, y amigo de Alemán, el alférez Valdés, lo elogia por haber sido «el primero que hasta hoy con estilo semejante ha sabido descomulgar los vicios con tal suavidad y blandura» (p. 470). Puesto que las doctrinas de Alemán apenas son originales («No todo es de mi aljaba; mucho escogí de doctos varones y santos» [p. 94]) la novedad estriba en su vehículo de transmisión, es decir, el relato de las andanzas de un pícaro, que cuando no enseña por su contrario amonesta directamente. Los lectores de Alemán que reflejaron sus opiniones en los preliminares de las ediciones de 1599 y 1604 percibieron que el viejo didactismo entroncaba con la novedad de un personaje calificado de pícaro. La generosa hipérbole del licenciado Miguel de Cárdenas no deja de ser una correcta interpretación de la posición de Alemán, capaz de emular a Homero, Virgilio, Cicerón y Petrarca desde «la humilde picardía» (p. 477).

López de Ubeda, poco después, se vanagloria de que «no hay enredo en $\mathrm{Ce}$ lestina, chistes en Momo, simplezas en Lázaro, elegancias en Guevara, chistes en Eufrosina, enredos en Patrañuelo, cuentos en Asno de oro [...] cuya nata aquí 
no tenga y cuya quinta esencia no saque». Y Justina, «novia de mi señor don Pícaro Guzmán de Alfarache», propone a éste «cabrahigar su picardía para que dure los años de mi deseo» ${ }^{39}$. El tono jocoso de tales manifestaciones no impide señalar dos consecuencias implícitas. La primera es que López de Ubeda agrupa obras formalmente muy diversas, sin encuadrar su relato dentro de un género determinado. La segunda es que lo distintivo de La picara Justina sería, además del personaje, el carácter misceláneo de la obra.

Por su parte, el personaje-autor de Estebanillo González ofrece una «relación verdadera», que supera a «la fingida de Guzmán de Alfarache», la «fabulosa de Lazarillo de Tormes» y «la supuesta del caballero de la Tenaza». En ella producen admiración, además de «los prodigios de mi vida», dichos agudos, enredos amorosos, diversidad de chanzas, flores de la fullería y las preeminencias de los pícaros de jábega. Aquí parece existir una conciencia más restringida de lo picaresco en lo que se refiere a las obras con que se rivaliza, e igualmente flexible en lo que atañe a la variedad de materiales que rellenan la biografía. Las hazañas picarescas (la faceta más visible) no impedirían, incluso propiciarían, la inclusión de otros elementos literarios.

De carácter parecido son las referencias que se localizan en Guitón Honofre ("pues ay primero y segundo pícaro, justo es darle compañero») o en Periquillo el de las gallineras («dejad la guía de un ciego a lazarillos y alfaraches, que vos tenéis algo de buen natural»). Tales ejemplos hacen pensar que la conciencia de los que llamaba Ginés de Pasamonte «aquél género» nació en torno a un personaje al que «por discretísimas aventuras que hizo le llamaron el pícaro», como escribe Espinel en Marcos de Obregón. Esa circunstancia explica, por otra parte, que en 1624 José Camerino pueda titular como El picaro amante un relato amoroso donde median engaños. La psicología y la condición social, más que la función literaria, son el rasgo destacado por estos vagos testimonios. Solamente en obras tan distintas como el Diálogo del Capón y el Quijote $(\mathrm{I}, 22)$ parece insinuarse la idea de que la narración autobiográfica debe acompañar a ese personaje. No es preciso comentar el célebre diálogo entre don Quijote y Ginés de Parapilla. En cambio, por ser menos conocido, merece ser transcrito lo que dice Velasquillo:

Serví después a un cura capón, que sin duda debió de ser pupilo del clérigo de Maqueda a quien sirvió Lazarillo de Tormes, y con todos estos me pasaron cossas de que pudiera haçer otro libro mejor que el suyo; y aunque voy abreuiando, no quiero pasar en silençio los quentos que me sucedieron con el cura capón. Diré algunos, por que si contase los que vi y los que oi, no cabrían en tanto papel como los libros del caballero de la Cruz o Amadís ${ }^{40}$.

39 Cito La pícara Justina por la edición de A. Rey Hazas, Madrid, 1977, I, pp. 81-2 y 83-4; Estebanillo González por la de Antonio Carreira y J. Antonio Cid Madrid, 1971, pp. 57 y 59, Guitón Honofre por la de Hazel Genéreux Carrasco, University of North Carolina, 1973, p. 112; Periquillo el de las gallineras, por la de Valbuena Prat, La novela picaresca española, 1974, II, p. 986.

40 Edición de Lucas de Torre, RHI, 38 (1916), p. 276. Modernizo la acentuación. 
Pero esas declaraciones no resultan concluyentes. Menos reveladores son los elogios de la vida libre que se localizan en diversos lugares (Guzmán, 1, II, 4 y 1, II, 5; Guzmán apócrifo, I, 2; Lazarillo de Juan de Luna, cap. VIII; Guitón Honofre, capítulo 12, etc.), parecidos a los de La ilustre fregona o La vida del pícaro. La mezcla de tópicos horacianos y parodia jocosa que suelen encerrar tales alabanzas no implica una definición formal de género. Son más bien, elementos adicionales que refuerzan la ambientación picaresca.

Estos indicios sugieren que la constatación de una tradición picaresca surgió ante los aspectos narrativos más visibles, es decir, personajes y aventuras. Casi un siglo después de la aparición del Pícaro persistía ese enfoque. En la división IX de El arca de Noé y la campana de Belilla, el personaje bíblico muestra a Francisco Santos «vna tropa de figurillas, en todo raras, meneando vnos libros»:

Aquel primero es Estevanillo Gonçález, vn Bufón que escrivió su vida; el otro es Rojas, el Comediante, que escrivió el Viage entretenido; el otra la Pícara Justina, el otro la Eufrosina; y el otro la Celestina: aquellos tres que están juntos, son los Autores de Guzmán de Alfarache, Lazarillo de Tormes, y Don Fruela; Essotros dos que faltan escrivieron el Mozo de los Frayles, y Lo que passa en vn Mesón, libros todos, y quanto contienen de bufonada y chulería, Alcahuetas y primeras Damas, y no nombro otros bien malos por la gravedad de sus Autores. Bien puede tu Periquillo el de las Gallineras sentenciarlos a fuego, que con aquel título presenta vna alma desengañada vestida de sentencia y moralida$\operatorname{des}^{41}$.

Puede decirse que a partir del Guzmán apócrifo de Sayavedra hubo conciencia expresa de una tradición picaresca, pero ésta no se tradujo en una concepción precisa desde el punto de vista formal. Los indicios examinados muestran la inexistencia de una divisoria entre relatos que hoy consideramos picarescos y obras que poseen, simplemente, tipos humanos equiparables a los pícaros. Por otra parte, la figura literaria del pícaro nunca se acomodó a un molde definido. Conoció especificaciones diversas, en lo caracterológico (mujer, bufón, virtuoso, escarmentado) y en lo funcional (escritor, narrador, conversador, mero personaje). Además, los relatos con pícaro (empleasen o no tal calificación del personaje) podían abarcar diversos temas y proyectarse, como así sucedió, en distintas direcciones ideológicas. Lo picaresco era una materia susceptible de ser conformada de los modos más diversos.

\section{Picaresca y sátira}

El comienzo de lo que hoy consideramos género picaresco tiene que situarse en 1555, cuando aparece la anónima Segunda parte. En cuanto primera imitación, hizo ver la posibilidad de otras. Recalcó, en palabras de Gonzalo Sobejano «la aptitud del Lazarillo primitivo para reengendrar en la España de entonces un

41 Edición de Fernando Gutiérrez, Barcelona, Selecciones bibliófilas, MCMLIX, p. 153. 
tipo de libro fictivo y satírico» ${ }^{42}$. Incluso motivó la aparición de una réplica: la Segunda parte, de Juan de Luna. La impresión conjunta de los Lazarillos de 1554 y 1555, a la vez que contribuyó a divulgar la continuación, pudo haber propiciado una lectura del Lazarillo de Tormes desde la actitud estética del relato de 1555. De hecho, la continuación de 1555 presenta rasgos técnicos y estructurales que, bien por influjo, bien por coincidencia fortuita, reaparecen en varios relatos posteriores, incluido Guzmán de Alfarache.

La Segunda parte no habría sido posible si su autor no hubiese visto en el modelo una crítica de estamentos y si él mismo no escribiese con propósitos parecidos. Lo mismo hay que decir de la génesis del Guzmán. Sólo la intención educativa de Alemán explica tanto la imitación del Lazarillo (o Lazarillos), como la introducción de notables modificaciones, encaminadas a extender e alcance de la sátira y a intensificar las digresiones teóricas. De esta forma, las primeras imitaciones y continuaciones del Lazarillo de Tormes surgen a causa del impulso crítico y correctivo de sus respectivos autores.

Muy a principios del siglo XVII, varios relatos se presentan como obras con pícaro, lo que permite afirmar que para entonces el género picaresco aparece bautizado como tal. Cuatro obras parecen responsables: los Guzmanes de Alemán y Martí, La pícara Justina y El Guitón Honofre. Los dos primeros relatos son indiscutiblemente didácticos, mientras que los dos restantes, a falta de mejor denominación, podrían calificarse como satírico-burlescos.

El flexible esquema de un pícaro itinerante se utilizó para mostrar tipos y situaciones, con o sin reflexiones teóricas. Varía en cada relato la dosificación de tales elementos, pero la subordinación del protagonista es una constante que ya afecta, al menos en parte, el primer Lazarillo y el primer Guzmán ${ }^{43}$. Resulta arriesgado especular sobre si la picaresca podría haberse desarrollado en una dirección distinta a la que siguió. Parece indudable, en cambio, que existió desde el momento en que sus cultivadores aplicaron sobre el hallazgo del pícaro una estructura y técnica satírica. Esa simbiosis hizo posible la reiteración con variantes que constituyen todo género.

Por la época en que se cultivó la narrativa picaresca la sátira podía ser entendida como un tipo de literatura que «trata particularmente aquella parte de la

42 Forma literaria y sensibilidad social, p. 25.

43 Para A. Rumeau (Le «Lazarillo de Tormes». Essai d'interprétation, essai d'attribution, París, 1964, pp. 5, 7, 8, 11 y 13) Lázaro de Tormes carece de verdadera evolución psicológica y no se diferencia sustancialmente de los héroes de El asno de oro o El Crotalón. Me parecen correctas sus observaciones acerca de la incoherencia del pregonero, pero excesivas al negarle toda profundidad psicológica. Tal vez sería más ajustado a la realidad distinguir en la caracterización de Lázaro dos técnicas: una, novelística, que se manifiesta en varios momentos de los tres primeros tratados; otra, escuetamente satírica: «Tout comme les satires de Boileau et de ses prédécesseurs. Et de tant d'autres» (p. 11).

Una dualidad parecida se da en Guzmán. La hondura que ponen de relieve muchos soliloquios no oculta incoherencias en su evolución, debidas a la manipulación de que es objeto por exigencias didácticas. Sorprende, por citar un ejemplo, que el Guzmanillo que ofrece tan ricas reflexiones sobre la vanidad de la honra (I, II, 2-4), diga poco más adelante que «en breves dias me refiné de jugador» (I, II, 5). Ese cambio no está presentado narrativamente, y sólo sirve para propiciar una reflexión sobre el peligro de los juegos de naipes (p. 285). 
Philosophía Moral que se dize Etica», habida cuenta, por otra parte, de que el oficio de los poetas satíricos es «emendar la vida» [...] «corregir vicios y costumbres malas» ${ }^{44}$. Esa voluntad de denuncia queda paladinamente expuesta en diversos prólogos, declaraciones y preliminares. A los ya muy conocidos pueden añadirse otros. Carlos García, por ejemplo, pide al lector que «espantado y temeroso [...] se quite de inconvenientes tan peligrosos como cada día se presentan al hombre». Castillo Solórzano indica que en Teresa de Manzanares el lector puede «advertir los daños que se pueden prevenir para guardarse de engaños, para abstenerse de vicios»; y que en el Bachiller Trapaza encontrará «un discurso sobre la rota vida de un embustero, escrita con el fin de que se guarden de los tales». El mismo autor advierte al comienzo de la garduña de Sevilla: «Sirva, pues, de advertimiento a los lectores esta pintura al vivo de lo que con algunas deste jaez sucede». Son declaraciones características de quienes crean personajes a la luz de principios satíricos.

En tal sentido, es representativa del horizonte estético en que se desenvolvieron varios narradores picarescos esta justificación de Marcos de Obregón:

El intento mío fue ver si acertaría a escribir en prosa algo que aprovechase a mi república, deleitando y enseñando, siguiendo aquel consejo de mi maestro Horacio; ${ }^{45}$

La narrativa picaresca emerge vinculada a tradiciones y gustos satíricos. De otro modo no se podrían explicar datos tan variados que apuntan a un mismo fin: declaraciones de propósitos, crítica de vicios, caracterización de los personajes, exhortaciones al lector, perspectiva narrativa, acarreo de fuentes didácticas, etc. La propia dinámica del género parece determinada en apreciable medida por la intención satírica (en el amplio sentido de la palabra), pues muchas imitaciones y continuaciones se sirven del modelo para inyectar nuevas críticas o moralizaciones.

La sátira, advierte Hodgart, «no constituye una categoría bien definida, sino una expresión conveniente para abarçar una gran variedad de obras literarias que tienen muchas características en común» ${ }^{46}$. Tal formulación tiene que resultar aceptable incluso para quienes interpretan bajo otro prisma la narrativa picaresca. En éste, además, convergen modelos satíricos específicos. Es decir, por utilizar los términos en litigio, no sólo el modo satírico, sino también algunos géneros satíricos.

Si Espinel alude a Horacio, Quevedo extiende por el Buscón reminiscencias de la sátira latina ${ }^{47}$. Más decisiva en la génesis de la picaresca parece haber sido la sátira menipea. En esa tradición cabe situar el Lazarillo de Tormes, vinculable

44 Philosophia antigua poética, edición de Alfredo Carballo Picazo, Madrid, 1953, III, p. 235; Introducción a la poética clasicista: Cascales, de Antonio García Berrio, Barcelona, 1975, p. 296.

45 Las citas proceden de La novela picaresca española, ed. de Valbuena Prat, II, pp. 100, 324, 430, 557 y I, p. 1152 .

46 La sátira, trad. española, Madrid, 1969, p. 8.

47 Cfr. Joseph Chorpenning, «Classical Satire and La vida del Buscón», Neophilologus, 61 (1977), pp. 214-19. 
a una obra tan significativa como El asno de oro ${ }^{48}$. La continuación de 1555 , con claros componentes lucianescos, entronca más claramente con aquélla. Y si se considera, con Bachtin, que la mezcla de «libera fantasía» y «naturalismo sordido» es un rasgo de la menipea ${ }^{49}$, entonces su ámbito abarca la Segunda parte de Juan de Luna, El coloquio de los perros y Gregorio Guadaña (en su marco El siglo pitagórico). Otros crítıcos quieren ver bajo esa influencia aspectos varios del Guzmán de Alfarache ${ }^{50}$. A su vez, características estructurales de la mayoría de los relatos picarescos (mezcla de géneros, libertad constructiva, alternativa de elementos cómicas y serios, parodia literaria) revelan su raigambre satírica, sea o no específicamente lucianesca ${ }^{\text {s1 }}$.

El mejor conocimiento de las concretas influencias satíricas ejercidas sobre el género picaresco permitirá avanzar en la descripción del mismo. Esta tarea, que necesita ser acometida, no implica desatención a cuanto en la picaresca hay de no satírica. Por ejemplo, las tradiciones narrativas que, sin la menor voluntad correctiva, se introducen en el género. Tampoco es factor desdeñable en su evolución el prurito de rivalidad con obras anteriores. Este tipo de emulación es patente en las relaciones de los diversos Lazarillos y Guzmanes. Lo es también en el

48 Para M. R. Lida de Malkiel, «lo distintivo del Lazarillo es la serie de amos, de suerte que el libro nació de veras al superar la deuda folklórica del Tratado I, quizá por inspiración del Asno de oro»; "La función del cuento popular en el Lazarillo de Tormes», Actas del Primer Congreso Internacional de Hispanistas, Oxford, 1964, 1964, p. 359. Se han ocupado de la posible influencia de Apuleyo: Margot Kruse, «Die parodistischen Elemente in Lazarillo de Tormes», RJ, X (1959), pp. 292-300; Jean Molino, «Lazarillo de Tormes et les Métamorphoses d'Apulée», BHi, LXVII (1965), pp. 323-33; Antonio Vilanova, «Un episodio del Lazarillo y el Asno de oro de Apuleyo», 1616, I (1978),pp. 189-97; del mismo autor, "L'Ane d'Or d'Apulée, source et modèle du Lazarillo de Tormes», L'humanisme dans les lettres espagnoles, ed A. Redondo, Paris, 1979, pp. 267-85; Joseph Ricapito, «The Golden Ass of Apuleius and the Spanish Picaresque Novel), RHM, XL (1978-79), pp. 77-85.

Como señaló Antonio Vilanova ( $L$ 'âne d'Or...», p. 267) la relación entre ambas obras («à mon avis incontestables») se efectúa a través de la traducción de Diego López de Cortegana, una de las obras clásicas más difundidas en España en torno al año 1540, según expone Théodore Beardsley, «La traduction des auteurs classiques en Espagne de 1488 à 1586, dans le domaine des Belles-Lettres», L'humanisme dans les lettres espagnoles, p. 63.

Luisa López Grigera ha mencionado un interesante testimonio donde Ramón Lull equipara a $L a$ zarillus con Apuleyo y Luciano, lo que parece reforzar la impresión de que los lectores del siglo XVI veían al héroe picaresco vinculado a la tradición representada por esos escritores. Cfr. «En torno a la descripción en la prosa de los siglos de oro», Homenaje a José Manuel Blecua, Madrid, 1983m p. 354 , n. 21 .

49 Dostoevskij, trad. italiana, Torino, 1968, p. 150.

50 George Peale, «Guzmón de Alfarache» como discurso oral», JHP, 4 (1979), pp. 431-47.

s1 Cfr. M. Bachtin, Dostoevskij, pp. 148-55; Gilbert Higuet, The Anatomy of Satire, Princenton, 1962, pp. 14-23; Ronald Paulson, The Fictions of Satire, Baltimore, 1967, pp. 56-73.

Constituye un dato de interés adicional el que Lazarillo de Tormes sea imitado en otras dialogales de clara condición satírica, como ocurre con los Colloquios de Baltasar de Collazos y el Diálogo intitulado el capón, cuyo análisis desarrolla Eugenio Asensio en $\mathrm{Cu} \mathrm{Hi,} \mathrm{280-82} \mathrm{(1973),} \mathrm{pp.} \mathrm{385-98.}$ No he tenido acceso a la primera de esas obras, por lo que sólo puedo remitir a las conclusiones que alcanza Eugenio Asensio en pp. 390-91. Respecto al Diálogo intitulado el capón, obra «de entretenimiento y risa, pero que tiene su moralidad y erudición» (p. 251 , ed. cit.), es una suerte de sátira menipea, que alterna escenas cómicas con disertaciones eruditas, por medio de una refundición de técnicas literarias muy variadas. Ambos diálogos, «que recogen y continúan con rumbos divergentes algunos elementos temáticos y formales del Lazarillo» (art. cit., p. 386), ponen de relieve la espontáneidad con que los lectores del XVI y XVII aproximaban el mundo picaresco a géneros y modos satíricos. 
caso de La pícara Justina y el Buscón con respecto al Guzmán (o, tal vez, Guzmanes). Con menos frecuencia se menciona el hecho de que tomas de posición similares se localizan, explícitamente, en Guitón Honofre, Estebanillo González o Periquillo el de las gallineras. No es fácil deslindar cuándo se escribe con fines satiricos y cuándo por puro alarde literario.

El peso de factores dispares en la formación de la picaresca, la confluencia de tradiciones narrativas distintas y el perfil tan difuso que posee la sátira hacen inevitablemente parcial cualquier marbete caracterizador del género. Por un lado, «lo picaresco» no tiene una forma narrativa precisa. La sátira, a su vez, tampoco. De ahí la fluidez del género picarescó y la imposibilidad (práctica y teórica) de fijar unos límites que no existieron ${ }^{52}$. Conviene, entonces, plantearse la idoneidad de la denominación habitualmente utilizada por los lectores de hoy.

\section{Picaresca y novela}

El sustantivo novela se agregó al adjetivo picaresca en un momento tardío. Según Erminio Braidotti en 1840, por obra de Eugenio de Tapia, secundado luego por Milá y Fontanals y Aribau ${ }^{53}$. En esos críticos la voz novela es empleada sin intención normativa ni descriptiva, en una acepción tan amplia como la que podrían tener «relato» o «narración». Lo distintivo de la novela picaresca para ellos no era ningún esquema constructivo, sino elementos temáticos y psicológicos: intención satírica, comicidad, moralidad, protagonista humilde. al caracterizar así el género, sin establecer ningún paradigma estructural, resulta en buena medida instrascendente el empleo o no de la palabra «novela». No sucede lo mismo cuando se pretende definir la picaresca a partir de un concepto más estricto de novela. Si se identifica a ésta con una forma de evolución psicológica, o con un determinado punto de vista, o con un específico empleo de las memorias, el uso terminológico adquiere consecuencias más hondas.

En un trabajo que data de $1962^{54}$, Claudio Guillén defendió la idoneidad del vocablo «novela» aplicado a la picaresca, porque ésta no se basa en una mera exposición de aventuras sino «on the interaction between a growing individual and his environment» (p. 77). De lo contrario, nuestro género «would not be a subgenre of what we call today the novel, or an integral stage in the emergence of the modern novel» (p. 77). A diferencia de lo ocurrido en Francia, en la picaresca española lo novelesco cierra el paso a sátiras del estilo de las anatomies of

52 «Since my contention is that the picaresque novel cannot be traced through a study of its formal characteristics [...] the awareness of continuing a perceived literary tradition is the only means we have for identifying a picaresque novel»; Howard Mancing, «The Picaresque Novel: a Protean Form», College Literature, 6 (1979-80), p. 191, así como p. 183, donde considera a la picaresca como un «undefinable genre».

53 "Genealogia y licitud de la designación novela picaresca», CuHi, 346 (1979), pp. 97-119.

54 «Toward a Definition of the Picaresque», Proceedings of the IIId Congress of the International Comparative Literature Association, ed. W.A.P. Smit, The Hague, 1962, reproducido posteriormente en Literature as System, Princeton, 1971, pp. 71-106, por donde cito. Los números entre paréntesis remiten a las páginas correspondientes. 
roguery: «In Spain —concluye- the anatomy will follow the novel, throught a process Montesinos has very rightly called 'desnovelización'» (p. 76, n. 6). La apuesta de Guillén en favor del carácter novelesco es tan decidida que insiste en que la escisión del héroe picaresco constituye «one of the most significant achievements of the picaresque, and perphaps its most substancial contribution to the thematics of the modern novel» (p. 89). Así, lo novelesco predomina sobre lo satírico, porque la crítica de vicios «is tempered with humor and the recognition of individual complexity» (p. 83).

No especifica Guillén cuántos relatos picarescos merecen el título de novelesco, pues su objetivo es distinguir entre novelas picarescas «in the strict sense» y novelas picarescas «in the broader sense». Con todo, ofrece varias indicaciones inequívocas. A la primera categoría parecen pertenecer tan sólo Lazarillo de Tormes y Guzmán de Alfarache. A la segunda, La hija de la Celestina y Bachiller Trapaza. No queda en claro en qué grupo entran el Buscón y La pícara Justina, aunque sí consta que son «picaresque novels». En cambio no es novela, sino anatomy of roguery, La desordenada codicia de los bienes ajenos (p. 76). Es novela, pero no picaresca, Marcos de Obregón.

Esta especie de trampa a que conduce el uso moderno de la palabra «novela» parece haber inducido a un uso más restringido. Así ocurre en el artículo de Lázaro Carreter, «Para una revisión del concepto de novela picaresca», vinculado en algunos aspectos al de Claudio Guillén. Tras aclarar que lo propio de la novela, «en el sentido actual del término», es que los personajes asuman su vida anterior y obren condicionados por ella en todos y cada uno de los momentos sucesivos de su existencia, Lázaro Carreter traza una clara divisoria:

Los relatos posteriores al Guzmán abandonan la trayectoria de la novela para desviarse hacia un límite, el de memorias o recuerdos de lances peregrinos, enristrados casi con técnica de Floresta ${ }^{55}$.

Simultáneamente ofrecía Francisco Rico conclusiones similares. En Lazarillo de Tormes, el autor logra «pensar desde dentro, con profunda simpatía novelística, a un personaje tan insignificante como el pregonero» [...] «También Alemán construye el personaje desde dentro»; «la rigurosa fidelidad a la primera persona $[. .$.$] indica la plena independencia, la integridad de Guzmán, en lo humano$ y en lo estético». Por el contrario, el resto de la picaresca, al «malentender la lección del anónimo quinientista y de Mateo Alemán», lejos de caminar hacia la novela moderna, «entraba en la vía muerta» ${ }^{56}$.

Así pues, dos novelas y una sucesión de relatos no novelescos. A partir de tales premisas, fácilmente se cede a la tentación de valorar la picaresca como promesa fallida: como el género novelístico que podría haber sido y no fue. Un ideal, al modo platónico, que la negatividad de la materia impidió realizar. Tal vez por

55 «Lazarillo de Tormes» en la picaresca, p. 216. Américo Castro consideraba que «La autonomia de la figura literaria es condición indispensable para el género novela, el cual se inició en España con La Celestina y el Lazarillo, y adquirió plenitud de desarrollo con el Quijote de Cervantes». Cfr. Hacia Cervantes, Madrid, 1967, p. 148.

56 La novela picaresca y el punto de vista, Barcelona, 1973, pp. 139-40. 
eso en tantos estudios de conjunto sobre la picaresca menudean las calificaciones negativas, una vez traspasada la frontera del análisis del Guzmán: epígonos, decadencia, incomprensión, construcción mecánica, desnovelización y otras similares. Lo sorprendente no es la legítima expresión, por parte del lector actual, de unas preferencias, sino el hecho de que éstas, en manos del historiador, sustituyen a la descripción de la evolución de la picaresca.

El pícaro, observó Claudio Guillén, «is not an independent hero who may be studied in vacuo» (p. 77). "Nuestro pícaro», confirma Francisco Rico, "surgió asociado a un esquema narrativo» (p. 131). ¿Fue éste la novela?. La constatación de la existencia de una narrativa picaresca parece tener lugar en los preliminares de la primera parte del Guzmán, en la «declaración para el entendimiento de este libro», en algunos versos de elogio de la Segunda parte de 1604 y en el título del apócrifo de Juan Martí. Pues bien, Guzmán, el Pícaro por antonomasia, fue considerado por Alonso de Barros «centro y abismo de todos [Los vicios]», concebido para «servir de ejemplo y dechado a los que se dispusieron a gozar de semejante vida». Gracias a ello, Alemán «ha conseguido felicísimamente el nombre y oficio de historiador, y el de pintor en los lejos y sombras con que ha disfrazado sus documentos y los avisos tan necesarios para la vida política y para la moral filosofía a que principalmente ha atendido» (ed. cit., pp. 97 y 98).

¿Fue leído Guzmán de Alfarache? — «escuela de fina política, ética y euconómica»- como lo que hoy se considera una novela?. Los testimonios de la época que he espigado no anulan los análisis críticos actuales, pero éstos no deben desconocer a aquéllos. Por lo demás, en la bibliografía sobre la caracterización de Guzmán se localizan opiniones muy variadas acerca de la consistencia psicológica del protagonista ${ }^{57}$. Tal vez nada define tan bien al héroe de Alemán como esta sintesis de Francisco Rico:

Concebida - sobre todo- como guía de la conducta, la Atalaya realiza magníficamente el didactismo originario, que explica en última instancia el recurso al personaje itinerante e inquieto - cuyo largo camino posibilita la denuncia de infinidad de situaciones y figuras humanas-o la forma autobiográfica - que da pie a las disertaciones abstractas integrándolas en el autorretrato del narrador ${ }^{58}$.

El Lazarillo de Tormes suscita consideraciones análogas. En las páginas anteriores he tratado de mostrar qué lectura propició en España durante los siglos XVI y XVII. Su pervivencia en otras literaturas no parece haber sido sustancialmente distinta. Un buen ejemplo lo constituye el Hungry Courtier Lazarello, que Beau-

57 Cfr. Moreno Báez, Lección y sentido del «Guzmán de Alfarache», Madrid, 1948, pp. 87-117; Sherman Eoff, "The Picaresque Psychology of Guzmán de Alfarache», HR, 21 (1953), pp. 107-19; Edmond Cros, Protée et le gueux, pp. 350-63; Alexander Parker, Los pícaros en la literatura, trad. esp. Madrid, 1971, pp. 80-86; Joan Arias, Guzmón de Alfarache: The Unrepentant Narrator, London, 1977, p. 95; Carrol Johnson, Inside Guzmán de Alfarache, Berkeley, 1978, pp. 215-29; Benito Brancaforte, Guzmán de Alfarache: ¿Conversión o proceso de degradación?, Madison, 1980.

58 «No de otro modo Luciano lleva a Menipo de escuela en escuela para poder dirigir sus dardos contra una buena serie de sistemas filosóficos», rubrica el citado crítico en nota a pie de página. Cfr. La novela picaresca española, p. CXLVIII. Con todo, la valoración que ofrece Francisco Rico del personaje de Guzmán de Alfarache es más novelesca de lo que pudiera sugerir el fragmento que entresaco. 
mont y Fletcher recrean en The Woman Hater ${ }^{59}$ (1607). Tampoco en un siglo como el XIX la fortuna del Lazarillo aparece vinculada a la renovación novelesca ${ }^{60}$. «Los lectores españoles - señala Dámaso Alonso- pensamos que el Lazarillo no es sólo un novela realista, sino que es aquella en que con más ascética sobriedad de medios se ha conseguido trazar inolvidables retratos llenos de vida, de unos cuantos personajes frecuentes en la España del siglo XVI» ${ }^{61}$. Pero C.A.: Jones, contrariamente, estima que el Lazarillo, lejos de ser un precursor de la narrativa moderna, es un survivor de la medieval ${ }^{62}$. Puede parecer tajante la posición de Rumeau cuando considera que «nous tombons dans l'anachronisme» al denominar novela al Lazarillo. Pero está llena de sugerencias la descripción de cómo ha ido imponiéndose una determinada lectura: «Pour les crítiques de l'âge du roman, enclins à voir un peu partout les «orígenes de la novela», le Lazarillo est devenu un roman picaresque, puis un roman tout court» ${ }^{63}$.

Al describir la picaresca como un proceso en declive desde la cumbre novelesca recien alcanzada se corre el riesgo de ofrecer una reconstrucción crítica sin relación con la conciencia que del género tuvieron sus cultivadores y lectores. Todo parece indicar que existió una «awareness of the picaresque itself as a tradition ${ }^{64}$; pero no hay testimonios de que se identificase con un patrón formal de carácter novelesco. A falta de declaraciones inequívocas, los narradores proporcionan ciertas pistas: los prólogos de algunos libros, el tema de la mayoría de los relatos, la técnica empleada, el objetivo de las continuaciones e imitaciones. Esos datos muestran que el género picaresco recibe la influencia de géneros y, sobre todo, modos satíricos. Sátira que abarca desde las elaboradas reflexiones de Alemán hasta las trilladas de Cortés de Tolosa o Francisco Santos. Sátira co-

59 Goe runne, search, pry in every nooke and Angle of the kitchins, larders, and pasteries, know what meates boyl'd, bak'd, rost, stew'd, fri'de, or sows'd, are this dinner to be serv'd directly, or indirectly, to every severall table in the Court, be gone». Esta intervención inicial indica claramente qué función cumple el personaje en la comedia. Cito por la edición de George Walton Williams, Cambridge University Press, 1966. Análoga lectura del personaje español ponen de relieve Middleton, (Blurt, Master Constable) y Fletcher, (Love's Cure, 1647), donde Lazarillo reaparece en el inalterable esquema de hungry servant.

60 Cfr. K.L. Selig, «Concerning Gogol's Dead Souls and Lazarillo de Tormes», Symposium, VIII (1954), pp. 138-40; G.O. Schanzer, «Lazarillo de Tormes in Eighteenth Century Russia», Symposium, XVI (1962), pp. 54-62; R. Guise, "La fortune de Lazarillo de Tormes en France au XIX siècle», $R e$ vue de Littérature Comparée, XXXIX (1965), pp. 337-57.

61 Tradición folklórica y creación artística en "El Lazarillo de Tormes», Madrid, 1972, p. 29. Y en La novela cervantina (Santander, 1969, p. 9) señala Dámaso Alonso dos obras cumbre en el análisis de procesos anímicos: «La Celestina en donde por primera vez la técnica del realismo psicológico ha plasmado grandes, intensos caracteres; y El Lazarillo de Tormes porque en él también por primera vez, esa maestría de raíz medieval ha ido a insertarse en una verdadera novela». Precisamente comparando esas dos obras M. Rosa Lida de Malkiel valora de distinto modo el Lazarillo, Cfr. La originalidad artística de «La Celestina», Buenos Aires, 1970, p. 609, n. 6.

62 "Lazarillo de Tormes: Survival or precursor?», Litterae Hispanae et Lusitanae, Munich, 1966, pp. 187-88.

63 «Notes au Lazarillo. Des éditions d'Anvers, 1554-1555, à celles de Milan, 1587-1615», $B H i$, 66 (1964), p. 293.

64 Como afirma Ulrich Wicks, «The Nature of Picaresque Narrative: a Modal Approach», $P M L A$, LXXXIX (1974), p. 245. 
mo amonestación grave, pero también como burla. Sin esa intención satírica (que no impidió otros propósitos), tal vez no habría nacido Lazarillo de Tormes. Y, desde luego, no habrían existido las interpolaciones de Alcalá, ni la Segunda parte de 1555; ni Guzmán de Alfarache, ni el Buscón, ni Guitón Honofre, ni la Pícara Justina, y así sucesivamente.

Como conclusión de todo lo anterior pueden proponerse las siguientes hipótesis de trabajos:

1. Para analizar el proceso de formación de la narrativa picaresca es preciso empezar por las continuaciones inmediatas del Lazarillo: las interpolaciones de Alcalá y la Segunda parte de 1555.

2. Si es razonable suponer una influencia del Lazarillo de Tormes en Guzmán de Alfarache, también lo es contemplar la posibilidad de que Alemán conociese el relato de 1555 . Y, en cualquier caso, no es posible soslayar las acusadas diferencias entre el relato de Alemán y su primer predecesor.

3. Los primeros relatos titulados como picarescos no pretenden mostrar un proceso psicológico, pues se sirven del pícaro como instrumento de crítica y amonestación. La figura literaria del pícaro, por otra parte, conoce desde el primer momento distintas derivaciones.

4. Para entender la formación y desarrollo de la narrativa picaresca es preciso tomar en consideración la influencia de la sátira, en sus distintas manifestaciones, si bien ésta tampoco explica la totalidad del género.

5 . Los testimonios que proporcionan los relatos y las declaraciones de sus autores sólo revelan conciencia de una simple tradición picaresca, nunca identificada con un molde narrativo concreto.

6. Las preferencias de los lectores actuales por unos relatos frente a otros no justifican la descripción en términos de maestros y epígonos.

7 . El término «novela» se aplicó tardíamente. Resulta contradictorio condicionar la descripción de una realidad literaria al mantenimiento de un sintagma, «novela picaresca», nacido de manera accidental. 